\title{
NOMEAÇÃO E INSTITUCIONALIZAÇÃO DA SAÚDE DO TRABALHADOR: UM CAMPO EM DISPUTA
}

\section{NAMING AND INSTITUTIONALIZATION OF THE HEALTH OF THE WORKER: A DISPUTED FIELD}

\author{
Ehideé Isabel Gómez La-Rotta (DD (0000-0003-1 194-9898) ${ }^{1,2}$, Claudia Regina Castellanos Pfeiffer (DD)(0000- \\ 0003-0331-9626) ${ }^{3}$, Heleno Rodrigues Corrêa-Filho (DD) (0000-0001-8056-8824) ${ }^{4}$, Carlos Roberto Silveira Cor- \\ rêa (iD) ${ }_{(0000-0002-9232-2263)^{1}}$, Francisco Hideo Aoki (iD) ${ }_{(0000-0002-9003-8488)^{5}}$, Clerison Stelvio Garcia ${ }_{(0000-}$ \\ $0003-0008-5481)^{6}$
}

\footnotetext{
${ }^{1}$ Universidade Estadual de Campinas, Faculdade de Ciências Médicas, Departamento de Saúde Coletiva, Campinas, São Paulo, Brasil. <larottaehidee@gmail.com>

${ }^{2}$ Universidade Militar Nueva Granada, Faculdade de Relações Internacionais, Programa de Administração da Segurança e Saúde Ocupacional, Cajica, Cundinamarca, Colômbia.

${ }^{3}$ Universidade Estadual de Campinas, Núcleo de Desenvolvimento da Criatividade, Laboratório de Estudos Urbanos, Campinas, São Paulo, Brasil.

${ }^{4}$ Universidade de Brasília, Faculdade de Ciências da Saúde, Departamento Saúde Coletiva, Brasília, Distrito Federal, Brasil.

${ }^{5}$ Universidade Estadual de Campinas, Faculdade de Ciências Médicas, Departamento de Clínica Médica, Campinas, São Paulo, Brasil.

${ }^{6}$ Centro Universitário Padre Anchieta, Curso de Psicologia, Jundiaí, São Paulo, Brasil.
}

\begin{abstract}
Resumo Considerando a dispersão de sentidos que constitui a nomeação da área 'Saúde do Trabalhador', buscou-se compreender o que está em jogo nas constantes mudanças da nomenclatura nesse campo. Essas alterações ocorrem em uma linha do tempo, mas concomitantemente. Seu marco inaugural foi encontrado na estabilidade do nome 'medicina do trabalho', nome institucionalizado pela Organização Internacional do Trabalho, no início da segunda metade do século XX. Desse primeiro gesto de nomeação, seguem outros, estabelecidos em relações tensas e contraditórias de substituição, recobrimento e concorrência como: saúde ocupacional, saúde e segurança no trabalho, e, mais contemporaneamente, em meio a estas variações, encontrou-se o acréscimo do termo 'Saúde do Trabalhador'. O penúltimo nome é o mais estável e acionado pelas instâncias internacionais e empresariais. Palavras-chave saúde do trabalhador; Organização Internacional do Trabalho; análise do discurso; saúde coletiva.
\end{abstract}

Abstract Based on the dispersal of meanings that constitutes the naming of the 'Health of the Worker' field, we sought to comprehend what is at stake in the constant changes in nomenclature in this field. These changes occur within a timeline, but they happen concomitantly. Its inaugural landmark was found in the stability of the name 'occupational medicine,' a name institutionalized by the International Labour Organization in the beginning of the second half of the 20th century. This first gesture of naming was followed by other gestures, established in tense and contradictory relationships of replacement, recovering and concurrence, such as: occupational health, health and safety at work, and, more recently, among these variations, we found the addition of the term 'Health of the Worker.' The second-to-last name is the most stable one, and it is used by international and entrepreneurial organizations.

Keywords health of the worker; International Labour Organization; discourse analysis; collective health. 


\section{Introdução}

Pode-se afirmar que o conhecimento das relações entre o trabalho e o adoecer secundário a acidentes ou à exposição a agentes nocivos no trabalho faz parte da história. Embora de modo esparso, há citações de acidentes de trabalho em diversos documentos antigos. Além desses episódios, também existem descrições sobre doenças provocadas pelas condições especiais em que o trabalho era executado.

As primeiras referências à associação entre a saúde, o trabalho e a doença foram encontradas em papiros egípcios e na civilização greco-romana, na Antiguidade, por volta de 1500 a.C. (Frias Junior, 1999; Waissmann, 2006). Mais de dois mil anos antes da nossa era, Hipócrates, conhecido como o Pai da Medicina, descreveu bem a intoxicação por chumbo encontrada em um trabalhador mineiro (Chagas, Salim e Servo, 2011).

Em 1700, o médico Bernardino Ramazzini publicou seu famoso livro De Morbis Artificum Diatriba, no qual descrevia, minuciosamente, doenças relacionadas ao trabalho encontradas em mais de 50 atividades profissionais existentes na época. Adicionalmente, indicava a incorporação de perguntas específicas sobre a ocupação durante a anamnese clínica, antecipando formas de prevenir e tratar enfermidades, como as osteomusculares, ainda prevalentes (Henriques, 2004; Ramazzini, 1999; Scliar, 2002).

Ramazzini teve um papel pioneiro no âmbito do desenvolvimento das disciplinas que se irão constituir à volta da problemática da saúde e segurança no trabalho, nas quais se incluem a medicina do trabalho, a higiene industrial, a patologia do trabalho e a epidemiologia social (Henriques, 2004). Apesar de a área ainda estar longe de ser constituída, é possível dizer que sua contribuição para o exercício da medicina do trabalho poderia ser resumida nos seguintes termos: interesse por um vasto grupo da população ativa até então ignorada e menosprezada pela medicina e pelos médicos no Ancien Régime: os artesãos; percepção dos principais determinantes da relação entre saúde e doença (ambientais, comportamentais, sociais); definição da metodologia de intervenção do médico do trabalho (recurso ao estado da arte ou revisão bibliográfica, visita aos locais de trabalho e observação direta, entrevista com o trabalhador, história ou anamnese profissional); abordagem clínica individual da doença ocupacional. Por fim, criação de perfis epidemiológicos de morbimortalidade causada pelo (ou relacionada com o) trabalho (Mendes, 2001; Scliar, 2002). No entanto, como será visto mais adiante, é apenas com a revolução industrial e com uma participação ativa do Estado que a medicina do trabalho começa a se institucionalizar.

Apesar dessas evidências, não há informação de qualquer ação que tenha sido proposta ou implementada para reduzir os riscos a que esses trabalhadores estavam submetidos. Nesses períodos, as vítimas dos acidentes e das doen- 
ças relacionadas ao trabalho eram quase exclusivamente escravos e pessoas oriundas de baixo estrato social (Chagas, Salim e Servo, 2011).

Foi somente após a Revolução Industrial e a consolidação do emergente capitalismo industrial que a necessidade de manutenção da saúde das pessoas no trabalho - preservação do corpo hígido do trabalhador - surgiu como construção social e política, sob responsabilidade explícita do Estado (Vasconcellos e Oliveira, 2007).

Dentro de uma narrativa da institucionalização deste espaço de intervenção, coube à cidade de Leeds, grande centro algodoeiro da Inglaterra no século XIX, ser considerada 'o berço da medicina do trabalho'.

Evidentemente, não se pode falar, especificamente, em medicina do trabalho. Nesta época, eles não passavam de 'serviços de medicina curativa' (curative health services), orientados para o trabalhador individual e para o diagnóstico e tratamento da doença. Eram fundamentados na abordagem da clínica geral. Tinham um papel passivo no local de trabalho e estavam desligados dos objetivos organizacionais da empresa. Entretanto, em uma época em que ainda não estava garantido o direito à saúde e aos cuidados de saúde, os serviços médicos das empresas tiveram, certamente, um papel importante na prestação de cuidados de saúde aos trabalhadores das grandes indústrias (Henriques, 2004).

Nesta narrativa, marca-se que, por volta de 1830, Robert Baker (18031880), autor de relatórios de saúde pública e futuro inspetor do trabalho, teria sido o primeiro médico que aconselhou um empregador a criar um serviço médico dentro de sua fábrica (Mendes e Dias, 1991).

O conselho de Baker representa, dentro dessa narrativa, a inauguração da Medicina do Trabalho. Esta especialidade médica torna-se responsável pela manutenção da saúde e do cuidado do trabalhador nas fábricas e é pensada como uma prática centrada na figura do médico, que se desloca para o estabelecimento produtivo e que se volta para o trabalhador adoecido, sem interferir nos fatores causais da enfermidade. Essa prática ocorre em um momento histórico, cujo consumo da força de trabalho, resultante da submissão dos trabalhadores a um processo acelerado e desumano de produção, exigiu a intervenção do Estado, sob pena, inclusive, de tornar inviável a sobrevivência e reprodução do próprio processo (Mendes e Dias, 1991).

Do ponto de vista deste estudo, há aí um gesto inaugural em torno de uma nomeação construída pela própria narrativa, que marca, empiricamente, um início para a área 'medicina do trabalho'. É com base nesta nomeação que se quer começar a construir um primeiro gesto de análise sobre os percursos de nomeação que a área vem recebendo.

Tais nomeações não são estáveis, nem entram em uma relação de mera substituição, mas sim de concorrência, de disputa por espaços de circulação. Em um mesmo tempo-espaço, várias nomeações são dadas, com significados 
diferentes, oriundas de diversas condições de produção'(Pêcheux, 1987), possibilitando distintas práticas a serem instaladas.

\section{As nomeações em torno da saúde do trabalhador}

Filiando-se à análise de discurso pecheutiana, propõe-se trazer à tela alguns dos diferentes modos de nomeação que circulam em torno da área da saúde do trabalhador. Esta teoria é fundada por Michel Pêcheux nos finais da década de 1960, na França, e ganha potência e desenvolvimento no Brasil por meio de Eni Orlandi, nos fins da década de 1970. De modo sintético, pode-se indicar que Michel Pêcheux articula, desestabilizando, três domínios disciplinares: a linguística (a língua - não como abstrata e nem como unívoca, mas histórica), o marxismo (o materialismo histórico - a história inscreve-se no mundo e, junto, inscreve o sujeito), a psicanálise (a subjetivação não psicologizada: o inconsciente). Para esta teoria, visa-se fazer compreender como os objetos simbólicos produzem sentido e, para tanto, analisam-se os próprios gestos de interpretação que são da ordem do simbólico também. A linguagem, portanto, para a Análise do Discurso, não é um instrumento de comunicação simplesmente, por duas razões fundamentais: não é um instrumento, já que o homem é atravessado pela memória; então, não 'controla' a linguagem a seu bel prazer. Não é comunicação porque, fundamentalmente, o que a linguagem faz é efetuar sentidos. Ela é o lugar em que o homem se faz sentido, para si e para os outros; é lugar da 'Constituição dos Sentidos' (Pêcheux, 1987).

Neste estudo, não será feito um trabalho exaustivo de análise. Neste momento, propõe-se levantar a questão como proposta para uma agenda de pesquisa e possibilidade de intervenção junto aos tomadores de decisões e aos formuladores de políticas públicas voltadas para a saúde do trabalhador que levem em conta a constituição, a formulação e a circulação dos sentidos (Orlandi, 2001).

Importa ainda esclarecer que esta proposta de uma agenda de pesquisa situa-se em uma posição teórica e política. O uso da Análise de Discurso de filiação pecheutiana para sustentar esta proposta justifica-se pela militância dos autores deste estudo no que se refere à saúde do trabalhador. Busca-se suspender as evidências postas em nossas trajetórias que naturalizam os nomes, inclusive o nome a que nos filiamos.

Nesse contexto, é importante que fique clara esta filiação a um conjunto de pesquisadores, autores, atores que vêm procurando estabelecer, como princípio norteador das políticas públicas, aquilo que preconiza a área nomeada de 'Saúde do Trabalhador' (Costa et al., 1989; Pimenta et al., 1988).

O objetivo deste estudo é compreender parte do que está em jogo nas constantes mudanças da nomenclatura nesse campo, partindo da dispersão 
de sentidos que constitui a nomeação da área 'Saúde do Trabalhador', assim como descrever o que constituiu a expressão 'saúde do trabalhador' no contexto brasileiro de emergência da prática de Saúde Coletiva, ou Saúde Pública, voltada para as pessoas que trabalham.

\section{Medicina do Trabalho - um nome}

No nome 'Medicina do Trabalho', encontra-se a ausência do sujeito assalariado - o trabalhador. Como as ausências e as presenças significam discursivamente, interessa destacar também o termo 'medicina', colocado ao lado de 'trabalho' e não 'saúde', ao mesmo tempo em que é o 'trabalho' que é posto ao lado de 'medicina' e não o 'trabalhador'. Aqui, lança-se mão de um exercício parafrástico ${ }^{2}$ como metodologia para compreender um pouco do processo de significação em funcionamento neste nome:

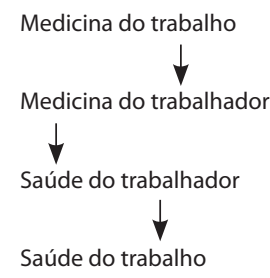

Na relação entre medicina e saúde, encontram-se a tensão, dentro de uma 'memória discursiva' 3 do campo das ciências médicas, entre uma prática tomada, exclusivamente, por um conhecimento biomédico e uma prática que inclui em suas ações outras dimensões do indivíduo, como o social, o político, o econômico, o subjetivo.

Além disso, em 'medicina', estreitam-se as possibilidades de atuação e de gestão das formulações a um único profissional e, portanto, lugar de reflexão e de atuação: o médico. Já em 'saúde', amplia-se o espectro daqueles que podem participar das ações e formulações do campo: os profissionais da saúde. Na relação entre trabalho e trabalhador, enfatiza-se ora aquele que detém os meios de produção, ora aquele que detém o corpo como força de trabalho. Esse pêndulo implica fortemente nas práticas envolvidas e oscila entre medicina, saúde, trabalho e trabalhador. Precisa ser guardado para se voltar a algumas das condições de produção do percurso de institucionalização da área que, apesar de parecer estabilizá-la em uma linha cronológica, linear e coerente, como se estivesse tratando sempre dos mesmos objetos, questões e práticas, mostra uma constante disputa de sentidos que repõe, deslocando, um lugar para esta disciplina/área e os diferentes nomes a ela atribuídos. 
Dito de outro modo, o que está se apontando é que diferentes nomeações vão sendo construídas no decorrer da história e não indicam sempre os mesmos sentidos, bem como não necessariamente retratam sentidos distintos. Estas diferentes nomeações assinalam, portanto, 'mesmos e outros' sentidos das práticas envolvidas naquilo que é designado como Saúde do Trabalhador.

\section{Da Medicina do Trabalho para a Saúde Ocupacional: outro nome, outros deslocamentos}

É interessante observar que, desde a apresentação, em 1832, ao Parlamento inglês, por Michael Sadler (1780-1835), da primeira lei escrita para a proteção dos trabalhadores, há uma série de práticas e ações dela decorrentes. Exemplos disso são o Factory Act of 1833, a criação do Factory Inspectorate e a ressignificação da presença dos médicos nas fábricas como peritos na 'certificação da idade mínima' para o trabalho fabril (nove anos na indústria têxtil). Além disso, os decorrentes serviços advindos dessas práticas expandiram-se para outros países da Europa, paralelamente ao processo de industrialização e, posteriormente, aos países periféricos, com a transnacionalização da economia. A inexistência ou fragilidade dos sistemas de assistência à saúde fizeram com que os serviços médicos de empresas passassem a exercer um papel vicariante. Consolidou-se, ao mesmo tempo, sua vocação como instrumento de criar e manter a dependência do trabalhador (e, frequentemente, também de seus familiares), ao lado do exercício direto do controle da força de trabalho.

A provisão de serviços médicos aos trabalhadores começa a fazer parte da agenda da Organização Internacional do Trabalho (OIT), criada em 1919, logo após o final da Primeira Guerra Mundial. O Tratado de Versalhes, do qual o Brasil foi um dos signatários, mudou, acentuadamente, o ritmo e o enfoque das normas e práticas de proteção à saúde dos trabalhadores, sendo, atualmente, referência internacional sobre o assunto (Becker, 2011).

Importa ressaltar que esta necessidade de normatização, no fim da Primeira Grande Guerra, indica outra imposição pujante por parte do bloco vencedor: a de que não houvesse mais trabalho escravo ou aviltado, ou mal pago, que pudesse interferir na composição dos preços dos produtos vendidos.

Entre as premissas para a constituição da OIT tinha-se o desejo de diminuir o trabalho escravo ou mal remunerado, considerando "que existiam condições de trabalho que implicavam para grande número de indivíduos, miséria e privações, e que o descontentamento que daí decorresse poderia pôr em perigo a paz e a harmonia universais". (Becker, 2011, p. 2), podendo intervir na composição dos preços dos produtos vendidos sendo uma das preocupações pelo que foi claramente dito na Declaração de Filadelfia (1944) 
“[...] é preciso a ação eficaz no plano internacional e nacional, [...] através de medidas que tendam a promover a expansão da produção e do consumo, a evitar flutuações econômicas graves, [...] a assegurar uma maior estabilidade dos preços mundiais das matérias-primas e dos gêneros e a promover um comércio internacional de elevado e constante volume [...]", sendo necessário a implementação em todas as nações membros da ONU "considerando que a não adoção por qualquer nação de um regime de trabalho realmente humano cria obstáculos aos esforços das outras nações." (Declaração de Filadélfia 1944, anexo III, p. 21).

Destaca-se que, em 1953, por meio da Recomendação 97 sobre a 'Proteção da Saúde dos Trabalhadores', a Conferência Internacional do Trabalho indicou aos estados membros da OIT que fomentassem a formação de 'médicos do trabalho' qualificados e o estudo da organização de 'Serviços de Medicina do Trabalho'. Observa-se aí a manutenção, ainda na metade do século XX, de termos correlacionados à nomeação 'Medicina do Trabalho' ao lado de um novo sintagma: 'proteção da saúde dos trabalhadores'. Na década de 1950 do século XX, este sintagma ainda não se consolida como um nome, mas como objeto de um nome: a saúde dos trabalhadores é objeto dos serviços da medicina do trabalho.

Em 1959, a Conferência Internacional do Trabalho aprova a Recomendação $112^{4}$, sobre 'Serviços de Medicina do Trabalho'. Este instrumento normativo de âmbito internacional passou a servir como referencial e paradigma para o estabelecimento de normas nacionais e é nele, aliás, que se baseia a norma brasileira. Este documento aborda aspectos que incluem a sua definição, os métodos de aplicação da Recomendação, a organização dos Serviços, suas funções, pessoal e instalações e, ainda, meios de ação. Ressalta-se, aqui, o título da recomendação 112: 'Serviços de Medicina do Trabalho'. Nele, mantém-se e consolida-se a designação 'Medicina do Trabalho', apagando a anterior Proteção da Saúde dos Trabalhadores - que, como visto, configura-se apenas como objeto de uma ação, a dos serviços médicos. Além disso, por meio da flexão de plural em 'serviços', outras possibilidades de atuação são abertas.

Nesse contexto, percebe-se a necessidade da participação de outros saberes e habilidades, além dos do profissional médico, para que haja uma atuação de prevenção mais efetiva das doenças e dos acidentes. Dessa forma, entram em cena três profissionais: o engenheiro, o profissional da higiene industrial e o profissional da Ergonomia.

O engenheiro é o encarregado das condições de segurança da maquinaria industrial, dos processos produtivos e do aperfeiçoamento dos equipamentos de proteção pessoal. O profissional da higiene industrial é responsável pelo reconhecimento, avaliação e controle dos fatores ambientais e de estresses originados no local de trabalho. Por fim, o profissional da Ergonomia estuda e procura a adaptação do trabalho ao ser humano. Constitui-se, assim, uma 
equipe multidisciplinar composta por profissionais nomeados como especialistas em Saúde Ocupacional, a qual ganha corpo com o esforço de reconstrução pós-Segunda Guerra Mundial, pelo consequente aumento de cargas de trabalho que originaram mais acidentes e doenças, quando fica patente a relativa impotência da medicina do trabalho para intervir sobre os problemas de saúde causados pelos processos de produção (Corrêa Filho et al., 1999; Hussey, 1948; Mendes e Dias, 1991, p.343).

Nesse longo trajeto das Recomendações que permitem a construção de um ir e vir em torno da medicina do trabalho e da saúde ocupacional, observa-se que há uma alternância contínua entre Medicina e Saúde, sendo que a medicina é 'do' trabalho, enquanto a saúde é 'ocupacional'.

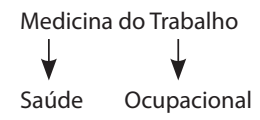

Seriam 'trabalho' e 'ocupacional' dois atributos distintos? O 'trabalho', precedido pela preposição 'de', torna-se um atributo de algo ou de alguém; no caso, de 'Medicina', indicando, também, um lugar - esta medicina acontece no trabalho. Por outro lado, 'ocupacional' é um adjetivo formado por sufixação do substantivo 'ocupação' e significa qualidade ou característica de algo, no caso, de 'saúde'.

Seria possível, pois, parafrasear saúde ocupacional por saúde da ocupação.

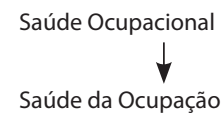

Há diferença aí? Esta ocupação é parafraseável com o trabalhador? Saúde do trabalhador? Acredita-se que não. De ponto de vista deste estudo, há, ainda, o foco no espaço do trabalho ou na característica de uma ocupação profissional que ocorre em um determinado espaço, mas não no sujeito trabalhador, o que pode ser observado nas seguintes paráfrases:

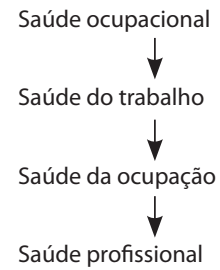


No entanto, o processo implicado nesta 'ocupação' está pressuposto, diferentemente de 'trabalho', em que o pressuposto é o local e não o processo que envolve um profissional. Entretanto, ainda caberia perguntar: Há uma diferença entre atribuir este lugar de trabalho ou esta ocupação à medicina ou à saúde? Acredita-se que sim. Há uma memória discursiva que ressoa e indica uma filiação da forma material 'medicina' a uma posição analítica sustentada por um discurso biomédico que decompõe o ser humano em planos: laboratorial, anátomo-patológico e clínico-epidemiológico. Em contrapartida, há uma forma material 'saúde', que se filia, nesta memória discursiva, a um todo completo, indiscernível e indivisível.

A medicina, ou ciência médica, como é expressivamente, e talvez, descuidadamente, rotulada, comporta um sem-número de disciplinas do conhecimento científico, para alcançar seus objetivos. Antes, quando a medicina não comportava especialidades, havia uma natural abordagem holística do ser humano em que a medicina buscava o 'bem' finalístico da cura, independentemente dos fatores determinantes dos desequilíbrios do 'andar natural das coisas da vida'. À medida que se complexificaram as variáveis de abordagem, e o conhecimento científico foi se acumulando, a medicina-ciência foi se subdividindo para dar conta dos níveis de exigência requeridos nos campos específicos do conhecimento necessário para atingir o 'bem' finalístico, mas dividindo o indivíduo em múltiplas partes (Vasconcellos e Pignati, 2006). Enquanto isso, o termo saúde - etimologicamente, no Inglês Antigo, 'hælp' expressa: "totalidade, um ser completo, som ou bem"; para o protogermânico 'hailitho': “todo, ileso, de bom presságio" (Etymonline, 2016).

Assim, em 'medicina do trabalho', há a indicação de uma decomposição do indivíduo (sistemas, órgãos, células, átomos), do mesmo modo em que se dividem os locais nos quais essas pessoas desenvolvem seu trabalho. Essa decomposição e divisão são feitas, a princípio, por uma área - a da medicina: ou seja, uma avaliação, tanto do indivíduo biológico como do posto de trabalho.

Por outro lado, em 'saúde ocupacional' essa indicação diz respeito a múltiplos profissionais (médico, fonoaudiólogo, terapeuta físico, enfermeiros, cientista social entre outros), com base em uma memória holística e integradora. Dessa forma, o indivíduo é analisado como um todo, em sua relação com as diferentes características das ocupações, baseando-se no conhecimento de diferentes áreas (como engenharia química, mecânica e industrial); ou seja, a análise pressupõe correlações entre ocupações e riscos de doenças derivadas destas ocupações.

Com o risco de ser redundante, é possível dizer que há a presença de 'saúde' no lugar de 'medicina' e de 'ocupacional' no lugar de 'trabalho'. É importante salientar que essa rede de substituição é já um deslocamento importante, pois o que está em jogo é o resultado de um processo: estar saudável ou, ainda, a busca por este estado. Diferentemente, a 'medicina' traz consigo 
um lugar autorizado de um conhecimento normalmente vinculado ao discurso biomédico, que dita o conjunto de procedimentos a serem seguidos. No caso de 'saúde', haveria, a princípio, espaço para mais saberes e discursos que constituíssem o conhecimento para se alcançar algo: o estado saudável. Por seu lado, em 'ocupacional', tem-se a flexão derivacional com base no sufixo 'al' que indica a formação de um adjetivo relativo à ocupação ou ao trabalho. Importa observar que a referência é o processo em que um sujeito se insere: a prática cotidiana de seu trabalho. Não é o mesmo que dizer 'saúde do trabalho', uma vez que, na construção daquele adjetivo - ocupacional - vincula a saúde a um processo em que um indivíduo está implicado e não a um estado ou lugar dos meios de produção, esvaziado da força de trabalho inscrita no corpo. Do mesmo modo, também não se poderia dizer que é a expressão equivale à 'saúde do trabalhador', uma vez que em 'trabalhador' há a explicitação deste indivíduo implicado nas práticas econômicas e políticas que envolvem as relações trabalhistas.

Importa observar ainda que, neste instrumento das Recomendações, e com base nos conhecimentos da higiene e da segurança no trabalho, é desenvolvida a avaliação. É também no momento pós-guerra que entra em cena 'avaliação' e 'qualidade', trazidas pelos especialistas estadunidenses para os países devastados pela guerra (Deming, 1982; Juran e Godfrey, 1998; Juran, Gryna e Bingham Jr, 1990). O gerenciamento de riscos também foi uma prática iniciada no período pós-guerra. Entende-se gerenciamento de riscos por processo global de estimar a magnitude do risco para um indivíduo, grupo, sociedade ou meio ambiente para, assim, decidir se o risco ${ }^{5}$ (Bernstein, 1997) é ou não tolerável ou aceitável (Covello et al., 1987; Gratt, 1987). Caberá ao Estado o dever do controle destes riscos ${ }^{6}$ (Brasil, 1988, p.119; Brasil, 1990), abertura para um novo deslocamento na dança das designações.

\section{Saúde e Segurança do Trabalho, outra estabilização}

No interior dessa abertura para novos profissionais da saúde ocupacional, encontramos outra disputa que vai ganhando força entre as designações da área. No site da Associação Brasileira para Prevenção de Acidentes (ABPA, 2018), é possível verificar que, no Brasil, a Portaria Ministerial do Trabalho n. 3.237, de 1972, institui o nome 'Saúde e Segurança do Trabalho' conforme prática norte-americana documentada em livros da Association Advancing Occupational and Environmental Health da década de 1970.

Em 1981, na Conferência Geral da Organização Internacional do Trabalho, convocada em Genebra pelo Conselho de Administração da Repartição Internacional do Trabalho, na sua $67^{\mathrm{a}}$ sessão, a OIT adota diversas proposições relativas à segurança, à higiene e ao meio ambiente de trabalho, sendo no- 
meada pela Convenção 155 como Segurança e Saúde dos Trabalhadores (OIT, 1981). É reformulada em 2006, através da Recomendação 197 (OIT, 2006), sendo ratificada fugazmente no Brasil, com o nome de 'Marco promocional para a segurança e saúde no trabalho'.

Importa observar que neste vai-e-vem, o nome que fica é marcado pela ausência do 'trabalhador' e do 'ocupacional', retornando para o sintagma 'do trabalho' tal qual em 'medicina do trabalho'. Mantém-se 'Saúde' com o acréscimo de 'Segurança', lembrando que ambas se ligam a 'Trabalho' por meio do pronome possessivo 'de', estabelecendo uma relação de posse: o trabalho possui saúde e segurança. É, pois, o trabalho ${ }^{7}$ - forma metonímica e metafórica dos meios de produção - que precisa ser seguro e saudável. A pergunta que fica é para quem? Para quem é seguro e saudável?

\section{Na direção da Saúde do Trabalhador - um nome e muitas disputas}

Apesar do enfoque multiprofissional e da inclusão de vários saberes técnicos, as mudanças advindas da implantação da Saúde Ocupacional ou da Saúde e Segurança do Trabalho, não alcançam os resultados esperados, faltando unidade nas proposições, além da deficiente formação profissional sobre o assunto.

Assim, no dizer de Mendes e Dias (1991), as atividades para melhoria das condições apenas se justapõem de maneira desarticulada e são dificultadas por lutas corporativas, pari passu à manutenção de altos índices de acidentes de trabalho, em especial nos países em desenvolvimento. A insuficiência da saúde ocupacional e da saúde e segurança do trabalho não foi um fenômeno pontual e isolado; foi um 'processo' contínuo (Mendes e Dias, 1991, p.344). Embora guarde certa 'especificidade' do campo das relações entre trabalho e saúde, teve sua origem e desenvolvimento determinados por cenários políticos e sociais mais amplos e complexos. Além disto, ainda que este processo tenha traços comuns que lhe conferem certa 'universalidade', ele ocorreu em ritmo e natureza próprios, refletindo a 'diversidade' dos mundos políticos e sociais e as distintas maneiras de os setores do trabalho e da saúde se organizarem (Oddone, Marri e Gloria, 1986; Pimenta et al., 1988, p.167).

É assim que, no final dos anos 1960 e início da década de 1970, com o fortalecimento dos sindicatos dos trabalhadores químicos, de petróleos e de energia atômica nos EUA (Oil, Chemical and Atomic Workers International Union), a inclusão do trabalhador como 'participante' de seu próprio cuidado e saúde, começa a ser construída com base na práxis da nomeação ${ }^{8}$ (Canguilhem, 2012) de 'Saúde do Trabalhador' (Oddone, Marri e Gloria, 1986; Pimenta et al., 1988, p.167). 
Parte-se de dois pressupostos básicos: O primeiro é que o trabalhador detém um conhecimento a respeito de seu processo de trabalho que deve ser o ponto de partida para a formação de uma consciência crítica referente às relações entre saúde e trabalho. O trabalhador, mais que ninguém, sabe o desgaste cotidiano que o processo de trabalho acarreta a seu organismo. O segundo pressuposto é que o sujeito capaz de modificar a atual organização do trabalho no sentido de adequá-la ao homem e não ao lucro é o trabalhador coletivo, organizado através de suas entidades representativas, centrais sindicais e partidos políticos (Pimenta et al. 1988, p.167).

As discussões e embates em torno da luta política pela implantação do nome 'Saúde do Trabalhador' são fortalecidos pela construção coletiva de se alcançar meios de o trabalhador abandonar a passividade e alçar-se como sujeito ativo, exigindo e indicando o que deveria ser mudado (Corrêa Filho et al., 1999). Nestes anos, estabelecem-se os princípios e práticas da 'não delegação da saúde', da 'validação consensual', da 'não monetização do risco' e do 'grupo homogêneo de risco' (Berlinguer, 1987). “Nessa fase de construção do direito à saúde do trabalhador, encontramos a predominância de dois fatores básicos: a participação do trabalhador e a avaliação do ambiente de trabalho como um todo, e não como a soma de fatores independentes." (Oliveira, 2010, p.78).

Em paralelo à formação do surgimento da Saúde do Trabalhador, ocorreu a iniciativa de criação do Centro de Estudos da Saúde do Trabalhador e Ecologia Humana (CESTEH) da Fundação Oswaldo Cruz (Fiocruz). Foi uma proposta de unificar correntes discursivas que estavam em formação na sociedade brasileira. Essa ideia unia 'Saúde do Trabalhador' como expressão que vinha surgindo e à qual se contrapunha a expressão linguística 'Ecologia Humana'. Esta lutava pela hegemonia com base no discurso oficial do Ministério da Saúde, Fundação Oswaldo Cruz e Conselho Nacional de Desenvolvimento Científico e Tecnológico durante o último governo militar de João Batista Figueiredo e sob o comando do Ministro da Saúde Paulo de Almeida Machado. A Ecologia Humana se pretendia apartada do conflito capital e trabalho e negava a participação sindical direta. A criação do CESTEH pode ser entendida como uma busca de conciliação entre ambas as formações discursivas ${ }^{9}$ em 1985 último ano da última ditadura militar brasileira (Fiocruz, 2015; Porto, 2005).

A saúde do trabalhador, na luta interna às instituições, aparece em formas de práticas diferenciadas em distintos momentos e regiões, dentro de um mesmo país, mantendo os mesmos princípios: trabalhadores buscam reconhecimento em seu saber, questionam as alterações nos processos de trabalho, particularmente a adoção de novas tecnologias, exercitam o direito à informação e à recusa ao trabalho perigoso ou arriscado à saúde, buscando a 'humanização' do trabalho (Mendes e Dias, 1991; Oddone, Marri e Gloria, 1986).

Como descrito por Boccalon, e citado por Mendes e Dias (1991), e Corrêa Filho et al. (1999), a saúde do trabalhador estava marcada pela condição bá- 
sica da 'Organização Sindical implantada na fábrica', tendo por princípios: a recusa aos adicionais de insalubridade; a saúde não delegada ao patrão, nem ao médico, nem às instituições; a valorização da 'subjetividade operária'; o confronto coletivo; a luta primordialmente voltada pela prevenção e saneamento do ambiente do trabalho; e a participação sindical como elemento fundamental para a democratização das instituições sanitárias.

Embora no Brasil a expressão 'saúde dos trabalhadores' tenha sido empregada no movimento sindical nos anos $1979-1984^{10}$ (Clemente e Almazan, 2011, p.13), o conceito de Saúde do(s) Trabalhador(es) ganhou publicação indexada com Pimenta et al. ${ }^{11}$ (1988) e foi retomado por Lacaz (1996), com a decorrente sustentação no discurso da academia, dos serviços e dos sindicatos. A nomenclatura também foi apoiada na iniciativa da Organização Pan Americana de Saúde, que considerou 1992 como o Ano da Saúde dos Trabalhadores (Lacaz, 1996; Organización Panamericana de la Salud, 1992; Tennassee, 2001, p.12)

Importa salientar ainda que, nos anos 1990, a designação 'Saúde do Trabalhador' circula na Argentina e no Equador mediante contatos com brasileiros. Desse período em diante, esta designação deixa de ser usada apenas por um conjunto de atores no Brasil, passando a entrar na terminologia do NationalLibrary of Medicine (MESH, 2006) e dos Descritores em Ciências da Saúde.

Compreende-se, portanto, que o nome Saúde do Trabalhador consolida-se quinze a vinte anos depois do termo Saúde e Segurança do Trabalho começar a circular e de se tensionar com as nomeações já existentes (Brasil, 1972). Lembramos, por exemplo, que a Organização Mundial da Saúde (OMS) promoveu, em 8 de junho de 2006, uma reunião em Stresa, Itália, na qual foi, pela primeira vez, reconhecido e empregado o termo Saúde do Trabalhador, embora a OIT não tenha acompanhado a declaração da OMS (World Health Organization, 2006).

Diferenciando-se das anteriores, esta designação - Saúde do trabalhador - constitui-se pela afirmação do trabalhador como o sujeito a ser cuidado, a ter garantido seu estado saudável, deslocando, de maneira substantiva e significativa, o pressuposto das ações e práticas: não é o trabalho, o lócus, os meios de produção que são salvaguardados, mas sim o trabalhador. É em nome deste trabalhador e de sua saúde que os meios e modos de produção devem se adequar, e não o contrário.

\section{Considerações finais}

É importante lembrar que, de nossa posição teórica, os sentidos resultam de relações; um discurso aponta para outros discursos que o sustentam, assim como projeta dizeres futuros: não há começo nem fim para o discurso. Os 
sentidos textualizam-se na rede interdiscursiva e intertextual, inscrevendose nas palavras e, no nosso caso específico, nos nomes de uma área.

Foi deste lugar que descrevemos, com base na teoria da análise de discurso, parte dos determinantes histórico-ideológicos da construção de uma área que nomeamos como 'Saúde do Trabalhador', mas que, no entanto, vem sendo designada muito mais recorrentemente como 'Segurança e Saúde do Trabalho', concorrendo com outras nomeações como 'Medicina do Trabalho' e 'Saúde Ocupacional'.

Pudemos acompanhar o modo como vai se inscrevendo, no nome da área, o jogo tenso de disputa de sentidos e de relações de forças no contrapondo entre um discurso fundador - que se estabiliza no século XVIII, embasado nos prejuízos econômicos industriais e que é reforçado no tratado de Versalhes (Becker, 2011) e nos delineamentos da criação da OIT - e um discurso sobre a saúde do trabalhador.

A luta contínua pela consolidação do nome 'Saúde do Trabalhador', rivalizando com os outros nomes que silenciam a forma material 'trabalhador', ou mesmo a forma material 'saúde', permite que compreendamos que o paradigma do lucro e da produtividade já foi naturalizado. Centra-se no trabalho (local, maquinaria) e inclui o trabalhador não como um 'participante' de seu próprio processo de saúde-doença, senão como uma parte do processo produtivo que precisa ser saudável e seguro. Neste marco, o discurso hegemônico é a Segurança e Saúde do Trabalho, não 'no' Trabalho, e muito menos 'do Trabalhador'.

E, ademais, 'segurança' envolve também controle, algo que se assegura ("something which secures") ou que precisa ser assegurado porque corre risco de se danificar ("safety of a state, person etc."). O que corre risco? Fomos vendo que o risco é econômico e não humano.

Desse modo, pudemos compreender que o sujeito trabalhador está incluído neste processo apenas como um dos elementos da linha de produção que precisa ser harmônica, equilibrada, segura e saudável. Portanto, assim como qualquer outra máquina, o trabalhador pode estar em risco, mas, principalmente, diríamos, este trabalhador põe em risco o 'processo', mais especificamente, o resultado: o 'ganho monetário-lucro'.

Nesta tensão de relações de sentidos e de forças, nossa pergunta inicial - segurança e a Saúde do quê ou de quem - foi parcimoniosamente respondida, permitindo-nos uma profunda provocação com a qual finalizamos nosso texto: A área e as entidades criadas para a proteção do trabalhador, segundo este discurso já estabelecido e estabilizado da Segurança e Saúde do Trabalho, estão lutando pelo quê? 


\section{DESIGNACIÓN E INSTITUCIONALIZACIÓN DE LA SALUD DEL TRABAJADOR: UN CAMPO EN DISPUTA}

Resumen Partiendo de la dispersión de sentidos que constituye la designación del área 'Salud del Trabajador', se buscó comprender lo que está en juego en los constantes cambios de la nomenclatura en este campo. Estos cambios se producen en una línea de tiempo, pero de forma concomitante. Su marco inaugural se encuentra en la estabilidad del nombre 'medicina del trabajo', institucionalizado por la Organización Internacional del Trabajo a comienzos de la segunda mitad del siglo XX. A este primer gesto de designación le siguen otros, establecidos en relaciones tensas y contradictorias de sustitución, enmascaramiento y competencia, tales como: salud ocupacional, salud y seguridad en el trabajo, y más recientemente, en medio de estas variaciones, se encontró el agregado del término 'Salud del Trabajador'. El penúltimo nombre es el más estable y utilizado por las instancias internacionales y empresariales.

Palabras clave salud del trabajador; Organización Internacional del Trabajo; análisis del discurso; salud pública.

\section{Colaboradores}

Ehideé Isabel Gómez La-Rotta, Claudia Regina Castellanos Pfeiffer e Carlos Roberto Silveira Corrêa foram idealizadores e coordenadores do estudo e realizaram as análises em conjunto com Heleno Rodrigues Corrêa-Filho, Francisco Hideo Aoki e Clerison Stelvio Garcia. Heleno Rodrigues CorrêaFilho, Francisco Hideo Aoki e Clerison Stelvio auxiliaram na escrita do texto. Ehideé La Rotta, Claudia Regina Pfeiffer e Heleno Corrêa-Filho escreveram o manuscrito. Todos os autores leram e aprovaram o texto final.

\section{Financiamento}

O presente trabalho foi realizado com apoio do Programa Estudantes Convênio de Pós-Graduação - PEC-PG, de CAPES/CNPq - Brasil.

\section{Notas}

${ }^{1}$ As condições de produção (Pêcheux, 1987) dizem respeito às possibilidades de significação de um dizer construídas pela memória que é, ao mesmo tempo, histórica, ideológica, social. A memória do dizer é um saber discursivo (e não do indivíduo) que torna possível todo e qualquer dizer. Funciona sob a forma do pré-construído, do já dito, e sustenta cada tomada de palavra, disponibilizando dizeres que afetam o modo como o sujeito significa em uma situação discursiva dada (Pêcheux, 1987).

${ }^{2}$ No exercício parafrástico, observa-se o que se mantém e o que aponta para uma diferença de sentidos em possíveis redes de substituições projetadas no gesto de análise. O que se projeta no exercício parafrástico são formulações que circulam por diferentes espaços 
discursivos ou formulações inexistentes e que, por isso mesmo, também podem auxiliar na compreensão do que não é possível (nas condições de produção atuais) ser dito.

${ }^{3}$ É espaço de efeitos da lembrança, do esquecimento, das repetições, das redefinições, das rupturas e das transformações de sentido em um dado processo discursivo. É onde ocorre a existência de um corpo sócio-histórico de traços discursivos (Pêcheux, 1999). Enfim, é o trabalho histórico da constituição da interpretação.

${ }^{4}$ Convenção 161 no Brasil, mudando seu nome para 'Serviços de Saúde do Trabalho', com uma descontinuidade com o discurso anterior, não tendo-se claro o objeto do que se fala (OIT, 1985).

${ }^{5}$ De acordo com Bernstein (1997), risco é um neologismo de seguro, que se diz derivar do francês risqué que, por sua vez, deriva do italiano antigo risicare, que significa "ousar". Nesse sentido, risco é uma escolha e não um destino. Assim, nossa liberdade de escolha depende das ações que ousamos tomar (Bernstein, 1997, p.8).

${ }^{6}$ Art. 200. Ao Sistema Único de Saúde compete... II. executar as ações de vigilância sanitária e epidemiológica, bem como as de saúde do trabalhador; ... VIII. colaborar na proteção do meio ambiente, nele compreendido o do trabalho (Brasil 1988)

${ }^{7}$ Está-se afirmando que a forma 'trabalho' é que funciona como metáfora e metonímia dos meios de produção, porque ao mesmo tempo em que trabalho representa (pode estar no lugar de) os meios de produção (relação metafórica: uma palavra por outra), trabalho também é parte dos meios de produção (parte pelo todo; metonímia).

${ }^{8}$ Palavra-conceito, nos termos de Canguilhem, 1966 (Canguilhem, 2012)

${ }^{9}$ De acordo com Michel Pêcheux, por formação discursiva entende-se tudo aquilo que pode e deve ser dito, de formas variadas, como uma alocução, um sermão, um panfleto, uma exposição, um programa etc., segundo uma posição dada em uma conjuntura determinada (Pêcheux, 1969).

${ }^{10}$ As Semanas de Saúde do Trabalhador (SEMSATs), promovidas por sindicatos, em parceria com técnicos da Fundacentro, no período de 1979 a 1984, eram semanas de mobilização sindical e não veiculava a proposta de compor um marco regulatório, assistencial, de vigilância epidemiológica e de democracia participativa direta nas políticas locais de saúde para trabalhadores. Estavam dentro da ditadura militar no marco civil da denúncia restrita quando nem sequer se pensava em SUS ou na Constituição de 1988 - que viriam dez anos mais tarde. Essas semanas são referenciadas em artigos desde os anos 1990 e não têm publicação em periódicos da época. Os registros das SEMSATs existem nas prateleiras de bibliotecas do DIESAT, da Fundacentro, e sindicatos de Osasco e ABC Paulista. Não estão publicados em livros e revistas e não estão na internet em formato eletrônico a não ser por referências indiretas. Boa parte do fundamento das discussões das SEMSATs aconteceram no marco linguístico e estrutural da corrente de 'Saúde e Segurança do Trabalho' e isto é visível nas publicações de revisão mais recentes (Clemente et al. 2011).

${ }^{11}$ Ângela Vorcaro também fala, em 1988, da 'Saúde do Trabalhador', mas não a utiliza como expressão linguística semântica e sim como descritiva, centrando-se na 'Saúde' dos trabalhadores. Parafraseando-a: "A crise econômica e a saúde dos trabalhadores" (Vorcaro, 1988, p. 37). O termo não é referenciado por ela no sentido linguístico do método em que a repetição constrói um significado a ela atribuída. 


\section{Referências}

ABPA. Dia 27 de julho: dia nacional de prevenção de acidentes do trabalho. Disponível em: <http://www.abpa.org.br/component/content/ article/100-dia-27-de-novembro-dia-nacionaldo-engenheiro-e-do-tecnico-de-seguranca>. Acesso em: 12 dez. 2018.

BERLINGUER, Giovanni. Medicina e politica. 1. ed. São Paulo: Hucitec, 1987.

BERNSTEIN, Peter L. Desafio aos deuses: a fascinante história do risco. Rio de Janeiro: Campus, 1997.

BECKER, Jean-J. O tratado de Versalhes. São Paulo: Editora Unesp, 2011.

BRASIL. Ministério de Trabalho e Emprego. Portaria N. 3237 de 27 de julho de 1972 - Serviço especializado em engenheria de segurança, higiene e medicina do trabalho. Disponivel em: <http:// portal.mte.gov.br/data/files/8A7C816A4A5E0 1F7014A9C77EC3821BB/04\%20-\%20NR-04. pdf $>$. Acesso 26 de julho 2015. Diário Oficial da União, seção 1, parte 1, p.4 -18, 1978.

BRASIL. Constituição da República Federativa do Brasil. Brasília: Presidência da República. 1988. Disponível em: <http://www.planalto. gov.br/ccivil_03/constituicao/constituicao. htm>. Acesso em: 23 ago. 2014.

BRASIL. Lei n. 8.080, de 19 de setembro de 1990: Dispõe sobre as condições para a promoção, proteção e recuperação da saúde, a organização eo funcionamento dos serviços correspondentes e dá outras providências. Diário Oficial da República Federativa do Brasil, Poder Executivo, Brasília, DF, 1990. Disponível em: <http://conselho.saude.gov. br/legislacao/ lei8080190990.htm > . Acesso em: 23 ago. 2014.19 set. 1990.

CANGUILHEM, Georges. O normal e o patológico. Tradução: Maria Tjereza Redig de Carvalho Barrocas. 1. ed.1966, Rio de Janeiro: Forense Universitária, 2012.
CLEMENTE Carlos A.; ALMAZAN, Gilberto. Uma história sem heróis: registro da luta por saúde e segurança dos trabalhadores. São Paulo: Sindicato de Metalúrgicos de Osasco e região - Força Sindical. 2011. Disponivel em: $<$ http://issuu.com/forcasindical/docs/livro_ uma_historia_sem_herois_0e93e9bdccl0d5>. Acesso em: 23 ago. 2014.

CORRÊA-FILHO, H. et al. Tópicos sobre a saúde do trabalhador para a atuação da promotoria. Disponível em: http://www.academia. edu/924468/T\%C3\%93PICOS_SOBRE_A_ SA $\%$ C3\%9ADE_DO_TRABALHADOR_ PARA_A_ATUA $\%$ C3\% $87 \%$ C3\%830_DA_ PROMOTORIA. Acesso em: 14 maio 2017.

COSTA, Danilo F. et al. Programa de saúde dos trabalhadores. A experiência da Zona Norte: uma alternativa em Saúde Pública. Sao Paulo: Hucitec; Humanismo, Ciência e Tecnologia, 1989.

COVELLO, Vincent T. et al. Uncertainty in risk assessment, risk management, and decision making. New York: Plenum Pub Corp, 1987.

CHAGAS, Ana M. R.; SALIM, Celso A.; SERVO, Luciana M. S. Saúde e segurança no trabalho no Brasil: aspectos institucionais, sistemas de informação e indicadores. 1. ed. Brasília: IPEA, 2011.

DEMING, Williams E. Quality, productivity and competitive position. Massachusetts: Massachusetts Institute of Technology, Center for Advanced Engineering Study Cambridge. 1982. Disponível em: < https://trove.nla.gov.au/wor $\mathrm{k} / 21572118$ ?selectedversion=NBD2841024>. Acesso em: 14 maio 2017.

ETYMONLINE. Disponível em: < https://www. etymonline.com/>. Acesso em: 20 jun. 2016.

FIOCRUZ. CESTEH. Centro de Estudos da Saúde do Trabalhador e Ecologia Humana. Escola Nacional de Saúde Pública Sergio Arouca 
(ENSP). Disponível em: <http://www.cesteh. ensp.fiocruz.br/>. Acesso em: 26 fev. 2015.

FRIAS JUNIOR, Carlos A. S. A saúde do trabalhador no Maranhäo: uma visão atual e proposta de atuaçäo. Dissertação (Mestrado em Saúde Pública). Escola Nacional de Saúde Pública Sergio Arouca, Fundação Oswaldo Cruz, Rio de Janeiro, 1999.

GRATT, Lawrence B. Risk analysis or risk assessment: a proposal for consistent definitions. In: COVELLO, Vincent et al. Uncertainty in risk assessment, risk management, and decision making. New York: Plenum Pub Corp, 1987, p. 241-249.

HENRIQUES, Luís M. G. Politicas de saúde no trabalho: um inquérito sociológico às empresas portuguesas. Tese (Doutorado em Saúde Pública) - Escola Nacional de Saúde Pública, Universidade Nova de Lisboa, Lisboa, 2004.

HUSSEY, Bell. Engineering in industrial health education (Discussion). Occupational Medicine, v. 1, n. 1, p. 2-7, 1948.Disponível em:<https://academic.oup.com/occmed/ article-abstract/os-1/1/2/1625086?redirecte dFrom=fulltext $>$. Acesso em: 15 nov. 2017.

JURAN, Joseph; GODFREY, Blanton. Juran's quality handbook. New York: McGraw-Hill Book Company. 1998.

JURAN, Joseph; GRYNA, Franc; BINGHAM JUNIOR, Richard. Manual de control de la calidad. Tradução: Jose Maria Vallhonrat Bou. Barcelona: Reverté, 1990.

LACAZ, Francisco A. C. Saúde do trabalhador: um estudo sobre as formações discursivas da academia dos serviços e do movimento sindical. Tese (Doutorado em Saúde Coletiva). Universidade Estadual de Campinas, Campinas. 1996.

MENDES, Rene; DIAS, Elizabeth C. Da medicina do trabalho à saúde do trabalhador. Revista de Saúde Pública, São Paulo, v. 25, n. 5, p. 341-349, 1991. Disponível em: <http://www.scielo.br/scielo.
php?pid=S0034-89101991000500003\&script $=$ sci abstract\&tlng $=$ pt $>$. Acesso em: 12 abr. 2013.

MENDES, Rene. Resumo da vida e obra de Bernadino Ramazzini. Associação Nacional de Medicina do Trabalho (ANAMT), São Paulo, 2001. Disponível em: <http://155.185.2.46/ immagini4/ANAMT\%20-\%20Sobre \% 20 Ramazzini.htm>. Acesso em: 15 nov. 2017.

NATIONAL LIBRARY OF MEDICINE. Medical Subject Headings (MeSH). Bulletin of the Medical Library Association. Disponível em: $<$ http://www.nlm.nih.gov/mesh/meshhome. html>. Acesso em: 28 abr. 2017.

ODDONE, Ivar; MARRI, Gastone; GLORIA, Sandra. Ambiente de trabalho: a luta dos trabalhadores pela saúde. (Saúde em Debate) 1.ed.1977, São Paulo: Hucitec; Humanismo Ciência e Tecnologia, 1986.

OIT. Convenção sobre Segurança e Saúde dos Trabalhadores (C- 155). Aprovada na $67^{\mathrm{a}}$ reunião da Conferência Internacional do Trabalho (Genebra - 1981). Entrou em vigor no plano internacional em 11 de agosto de 1983. Disponível em: <https://www.ilo.org/ brasilia/convencoes/WCMS_236163/lang--pt/ index.htm>. Acesso: 15 jun. 2015.

OIT. Recomendação sobre o marco promocional para a segurança e saúde no trabalho (R197). 2006. Disponível em: < https://www.ilo.org/ dyn/normlex/es/f?p=1000:12100:::NO:1210 0:P12100_INSTRUMENT_ID:312534>. Acesso: 15 jun. 2015.

OIT. Recomendação sobre os serviços de saúde no trabalho (R117). 26 de junho de 1985. Genebra, $71^{\mathrm{a}}$ reunião CIT.

OLIVEIRA, Sebastião G. Proteção jurídica à saúde do trabalhador. São Paulo: LTr. 2010.

ORGANIZACIÓN PANAMERICANA DE LA SALUD. Diretrizes para um plan nacional de desarrollo de la salud de los trabajadores. Washington: OPAS, 1992.

ORLANDI, Eni P. Discurso e texto. Campinas: Unicamp, 2001. 
PÊCHEUX, Michel. Analyse automatique du discours. In: Gadet, Françoise; Hak, Tony. Por uma análise automática do discurso: uma introdução à obra de Michel Pêcheux. Tradução: Betânia Mariani et al., Campinas: Unicamp. p. 61-161, 1987.

PIMENTA, Aparecida L. et al. Saúde do trabalhador. São Paulo: Hucitec, 1988.

PORTO, Marcelo F. Saúde do trabalhador e o desafio ambiental: contribuições do enfoque ecossocial, da ecologia política e do movimento pela justiça ambiental. Ciencia e Saude Coletiva, v. 10, n. 4, p. 829-839, 2005.

RAMAZZINI, Bernardo. As doenças dos trabahadores [De morbis artificum diatriba: in patavino archi-lvceo]. Tradução: Raimundo Estrêla. São Paulo: Fundacentro. 1. ed. 1999.

SCLIAR, Moacyr. Do mágico ao social: trajetória da saúde pública. São Paulo: Senac, 2002.

VASCONCELLOS, Luiz C. F.; OLIVEIRA, Maria H. B. Direitos humanos e saúde no trabalho. Saúde e Direitos Humanos, v. 4, n. 4, p.113-134, 2007. Disponível em: <http:// www.unisc.br/portal/upload/com_arquivo/ politicas_publicas_e_movimentos_sociais_ hoje__ 97.pdf\#page $=113>$. Acesso em: 28 abr. 2017.

VASCONCELLOS, Luiz C. F.; PIGNATI, Wanderlei A. Medicina do Trabalho: subciência ou subserviência? Uma abordagem epistemológica. Ciência \& Saúde Coletiva, Rio de Janeiro, v. 11, n. 4, p.1105-1115, 2006. Disponível em: < https://www.researchgate. net/publication/250026649_Medicina_do_ Trabalho_subciencia_ou_subserviencia_ Uma_abordagem_epistemologica $>$. Acesso em: 28 abr. 2017.

VORCARO, Angela R. De que adoecem e morrem os trabalhadores? Psicologia: Ciência e Profissão. v. 8, n. 2, p. 37-38, 1988.

WAISSMANN, William. A "cultura de limites" e a desconstrução médica das relações entre saúde e trabalho. Tese (Doutorado em Saúde Pública) - Escola Nacional de Saúde Pública Sergio Arouca, Fundação Oswaldo Cruz, Rio de Janeiro, 2000.

WORLD HEALTH ORGANIZATION. Declaration on Workers Health. Seventh Meeting of the WHO Collaborating Centres for Occupational Health. Acesso em: 18 jun. 2006. 